\title{
Pareceres
}

\section{Imposto do Reajustamento Economico do Paraná}

Dr. Sampaio Doria

\author{
C O N S ULT A
}

Consulta-nos a "Companhia Indústrias Brasileiras de Papel":

1. ${ }^{\circ}$ se está obrigada a pagar, ao Tesouro do Estado do Paraná o "imposto de reajustamento econômico", a que se refere o decreto $n .^{\circ} 1.336$ de 29 de maio de 1934, do Governo do mesmo Estado, sobre as mercadorias recebidas pelos estabelecimentos industriais de sua propriedade sitos em Cachoeirinha;

2. ${ }^{\circ}$ si o imposto do "reajustamento econômico do Estado do Paraná" é ou não inconstitucional, e, portanto, se a sua cobrança, pelo governo do mesmo Estado, tem procedência.

Um pequeno histórico convem ao esclarecimento da pendência suscitada.

Em 1916, o Congresso legislativo do Estado do Paraná, no intuito de fomentar a indústria de papel, autorizou, pela lei 1.637 de 8 de abril de 1916, o. Poder Executivo a conceder ao dr. José Ferencz, ou á empreza que organizasse, estes favôres: 
1.") isenção dos impostos de exportação pelo prazo de 10 anos, para a polpa de papel, e para o papel que fabricasse com o pinho do Paraná; e

2.) isenção dos impostos de "Patente Comercial" para os maquinismos indispensáveis e destinados á fábrica "que pretendia fundar, bem como para o material accessório, não existente no país".

Baseado nesta autorização, o governo do Paraná assinou, aos 4 de maio de 1918, com o dr. José Ferencz, contrato em que se estipulou, na clausula II:

a) isenção de impostos de exportação pelo prazo de 10 anos, a contar da data da inauguração oficial da fábrica, para a polpa de papel e para o papel e seus derivados, fabricados com pinho do Paraná; e

b) isenção de impostos de Comércio para os maquinismos indispensáveis e destinados á fábrica, bem como para o material accessório, não existente no país.

Quatro anos depois, por uma lei nova, a de $n .^{\circ} 1949$, de 24 de março de 1920, reiterava o Congresso legislativo do Paraná ao seu Poder executivo autorização para:

"conceder á "The Oversea Company of Brasil", para a montagem de uma fábrica de papel de madeira e anexos, aproveitando, como matéria prima, o pinho do Paraná ou outra madeira, os favores constantes das letras $a$ e $b$ da lei n..$^{\circ} 1.637$ de 1916.

Os favores das letras $a$ e $b$ são os acima numerados, como $10^{\circ}$ e $20^{\circ}$.

Aos 10 de abril de 1920, foi lavrado o contrato entre a "The Oversea Company of Brasil" e o Governo do Estado. Está assim redigida a clausula primeira deste contrato: 
"E' concedido á "The Oversea Company of Brasil", ou á empreza que se organizar, para montagem neste Estado de uma fábrica de papel e polpa de madeira e anexos, aproveitando como matéria prima o pinho do Paraná os seguintes favores:

a) isenção dos impostos de exportação pelo prazo de dez anos para a polpa do papel e para o papel que fabricar com o pinho do Paraná;

b) isenção do imposto de comércio para os maquinismos indispensáveis e destinados á fábrica que pretende fundar, bem como para o material e accessório não existentes no país".

Em 22 de abril de 1920, a "The Oversea Company of Brasil" comunicava ao Governo o início da construcção da fábrica, e o Governo do Estado acusava, em oficio $n .^{\circ} 1.305$, de 12 de maio do mesmo ano, o recebimento da comunicação acima.

As obras foram ultimadas dentro do prazo contratual.

Mas a 11 de abril de 1921, a "The Oversea Company of Brasil" transferiu, por escriptura lavrada nas notas do Tabelião Veiga desta Capital, á "Companhia Indústrias Brasileiras de Papel" a fábrica e os direitos que lhe outorgara a lei paranaense de 1920, supra mencionada. E, em 1927, a mesma "Companhia Indústrias Brasileiras de Papel" adquiriu da "Sociedade Fábrica de Papel Iguassú Limitada", sucessôra do dr. José Ferencz, "todos os bens moveis, imóveis, privilégios e direitos de propriedade", que constituiam o seu patrimônio.

De tudo foi cientificado o Governo do Paraná.

o Congresso legislativo do Estado - já agora em contacto direto com a "Companhia Indústrias Brasileiras de Papel", decretou, e o Governo do Estado sancionou a lei n. 2.666, de 13 de abril de 1929, com um só artigo:

"Artigo unico -- Ficam prorogados por mais dez anos, os favores constantes das letras a) e b) do 
artigo primeiro da lei $n .^{\circ} 1.637$, de 8 de abril de 1916, concedidos á "Companhia Indústrias Brasileiras de Papel"; revogadas as disposições em contrário".

Quer, pois, dizer que, até 1939, a "Companhia Indústrias Brasileiras de Papel” está, por concessão legal, isenta de pagar ao Governo do Paraná:

1. ) impostos de exportação para o papel e polpa que fabrique com pinho do Paraná; e

2..$^{\circ}$ impostos de comércio para os maquinismos de suas fábricas, e para o material e accessório não existentes no país.

Ainda outro histórico, tão necessário como o anterior, á compreensão exata do desacôrdo surgido.

Em 1934, o Interventor Federal do Estado do Paraná substituiu, com o decreto n. $^{\circ} 146$, de 26 de janeiro de 1934, o imposto de comércio pelo de consumo. Está redigido assim o artigo primeiro deste decreto:

"Fica extinto o imposto do comércio, instituido pela

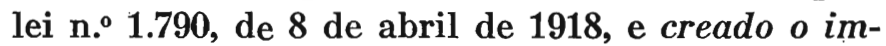
posto do consumo, que será regulamentado.

Quatro mezes depois, aos 29 de máio de 1934, o Interventor Federal naquele Estado, interventor interino, trocou, no imposto de consumo, o seu rotulo pelo de "reajustamento econômico". Que se trata, no fundo, de mudança apenas de nome é o próprio decreto 1.336, que se encarrega de o provar. Por estes considerandos:

considerando que o decreto $n .^{\circ} 146 \ldots$ e respectiva tabela aprovada para a cobrança de imposto de consumo sofreram várias modificações pelo decreto 1.024 ... 
considerando que... é indispensavel coordenar os dispositivos dos dois decretos referidos para que tenham fácil aplicação e interpretação segura;

já se tacteia o pensamento do Interventor que legislava.

Era o de consolidar os dois decretos, o que instituiu o imposto do consumo em substituição ao do comércio, e o de n..$^{\circ}$ 1.024, que o modificou. Não se trata, pois, apesar do batismo nominal, de um imposto novo. E' o anterior que passou a denominar-se de "reajustamento econômico".

Aliás, sobre esta identidade entre o imposto anterior e o de reajustamento, não é preciso inferir ou concluir, nem mesmos aduzir argumentos. $E^{\prime}$ o proprio decreto 1.336 que o proclama expressamente no artigo $3 .^{\circ}$, quando explica:

"O presente imposto... passará a denominar-se de "reajustamento econômico".

Se passa a denominar-se, é porque já existia com outra denominação. Não importa que, neste decreto, se fale em criação. $O$ artigo primeiro não se abalançou a tanto. Diz apenas:

Art. $10^{\circ}-0$ presente imposto recairá sobre os produtos incorporados á riqueza paranaense, e produtos destinados e expostos a venda...

Eis o segundo histórico, em resumo.

Baseado no artigo primeiro, acima transcrito, do decreto . $^{\circ}$ 1.336, o Inspetor Regional das Rendas no Estado do Paraná, por ofício n. ${ }^{\circ} 114$, datado, em Jaguariahyva, aos 2 de maio deste ano, intimou a "Companhia Indústrias Brasileiras de Papel" a pagar os impostos do "reajustamento econômico", nos termos do decreto n. 1.336 citado.

Julga-se, porém, a "Companhia" isenta deste imposto, e com razão.

Senão vejamos. 
Em primeiro logar, a inconstitucionalidade do decreto 1.336, de 29 de maio de 1934.

Dispõe o artigo primeiro deste decreto.

“O presente imposto recairá sobre:

- os produtos incorporados á riqueza paranaense, e - produtos destinados e expostos a venda, efetuados por industriais ou comerciantes em todo o território do Estado".

O decreto não diz, logo de inicio, que cria certo imposto. Começa dizendo "o presente imposto". Qual? Só pode ser o referido nos considerandos, isto é, o de consumo que substituiu nominalmente $o$ de comércio. $E$ tanto não se cuida de um imposto novo, que, logo adeante, no artigo 3 , declara o decreto que o imposto sobre que legisla, passará a denominar-se de "reajustamento econômico". Isto é, tinha uma denominação, a de consumo, e passará a chamar-se "reajustamento econômico".

Ora, o imposto do "reajustamento econômico" incide em duas ordens de produtos:

1.0) os incorporados á riqueza paranaense, e

2. ) os efetuados por industriais ou commerciantes, destinados ou expostos a venda.

Que são produtos incorporados á riqueza paranaense, ou, como diz um dos considerandos do decreto 1.336, "produtos rigorosamente incorporados ao patrimônio paranaense"?

Riqueza paranaense, ou patrimônio paranaense, são frases equívocas, impróprias numa lei. Patrimônio ou riqueza paranaense não se confunde por certo com o patrimônio do Estado, os bens do tesouro estadual. Deve constituir-se por todos os valores econômicos, que existem no Estado, pertençam a quem pertencerem, ao Governo como as terras devolutas, ou aos particulares, individuos ou empresas. 
E incorporação que vem a ser? Incorporar é entrar para o corpo. Não estava, mas passa a estar. As terras devolutas, por exemplo, nunca se incorporam. Já estão, ou já são o corpo. A incorporação só se pode dar com as riquezas que, desde o começo, não sejam o corpo, não estejam no Estado.

Logo, só se incorporam á riqueza paranaense, ou ao patrimônio paranaense, ao que já é esta riqueza ou patrimônio a que se incorpore, os valores econômicos, que venham de fóra.

Mas vir de fóra ou é vir de outro Estado, ou é vir de paizes estrangeiros.

O imposto que recair em mercadorias que venham do estrangeiro, é de importação.

0 imposto que recair em mercadorias que venham de outros Estados, é inter-estadual.

Mas, na primeira hipotese, o imposto contravém o artigo sexto, $\mathbf{n} .^{\circ}$, letra a, da Constituição Federal, que estatúe:

“Compete tambem privativamente á União:

I decretar imposto:

a) sobre a importação de mercadorias de procedencia estrangeira".

Logo, o imposto do "reajustamento econômico" do Paraná, na parte em que recae sobre produtos de importação, incorporados á riqueza paranaense, é inconstitucional.

Na segunda hipotese, a inconstitucionalidade é ainda mais manifesta.

O imposto inter-estadual e intermunicipal é vedado em termos lapidares, na Constituição da República. Parece ter havido, até, na Constituinte, a preocupação revoltada de gritar alto, para que ninguem se desculpasse, depois, de ter ouvidos moucos. Releia-se o texto constitucional, art. 17 n. ${ }^{\circ}$ IX.

“E' vedado á União, aos Estados, e aos Municipios: 
IX - cobrar, sob qualquer denominação, impostos inter-estaduais, intermunicipais, de viação, ou de transporte, ou quaisquer tributos que, no território nacional, gravem ou perturbem a livre circulação de bens e pessôas, e dos veículos que os transportarem".

Cobrar imposto, sob qualquer denominação, sobre mercadorias que se incorporarem á riqueza de um Estado, vindas de outro, é cobrar impostos inter-estaduais.

E' este preceito um dos maiores benefícios da organização federativa de um país. A ganância do fisco nem sempre sabe conter-se deante do interesse geral, como a queda de barreiras entre os Estados de uma federação. Mas é iniludível o preceito. Toda e qualquer lei estadual, que, embora sob o disfarce, ou a pompa, de uma denominação como "reajustamento econômico", importe em gravar a livre circulação de bens entre os Estados, é inconstitucional, e, pois, ninguem lhe deve obediencia.

Ora, o decreto n. ${ }^{\circ} 1.336$, de 29 de maio de 1934, do Estado do Paraná, obriga o pagamento de imposto sobre produtos incorporados á riqueza paranaense, isto é, sobre bens que se incorporarem á riqueza paranaense, vindos de oulros Estados.

E' praticamente imposto interestadual, que a Constituição veda.

A segunda ordem do imposto paranaense de "reajustamento econômico" é o que recae sobre produtos destinados ou postos a venda.

Que vem a ser semelhante imposto?

Desdobra-se, nos termos da lei paranaense, este imposto em duas incidencias:

1. ) produtos destinados a venda "efetuados" por industriais", e

2. ) produtos postos a venda, "efetuados" por comerciantes".

A redação da lei não é das mais puras. Mas dá para entender. 
0 imposto que recáia sobre produtos destinados ou postos a venda ou é de comércio ou é de consumo. Destinamse a venda? E' de comércio. São postos a venda? E' de comércio. Comércio, ou consumo.

Mas se fôr de consumo, o artigo 6 citado, letra $b$, da Constituição Federal, não permite aos Estados. Compete privativamente á União decretar impostas:

b) de consumo de quaisquer mercadorias, excepto os combustiveis de motores de explosão".

E se de comércio, a "Companhia Indústrias Brasileiras de Papel" dele se acha isenta, em virtude da lei, e do contrato, acima expostos.

De qualquer fórma não está a “Companhia Industrias Brasileiras de Papel" obrigada a atender á intimação do Inspector de Renda do Paraná, não está obrigada a pagar ao Tesouro do Estado do Paraná o imposto de "reajustamento econômico" de que trata o decreto $n .^{\circ} 1.336$, acima referido.

Não está, porque ou tal imposto é inconstitucional, ou dele está a "Companhia" isenta por lei.

$\mathrm{E}$ ' inconstitucional o que recae sobre mercadorias, que se incorporarem á riqueza do Estado, quer quando procedam do extrangeiro, quer quando procedam de outros Estados.

E' inconstitucional ainda o que recair sobre mercadorias a venda, por se confundir com o do consumo, cuja instituição é da competência privativa da União. Não importa que passe a denominar-se deste ou daquele modo. E', na incidência, imposto de consumo, que os Estados não podem cobrar.

o que restar, sem contravir a Constituição, o imposto de comércio, (e é o que, no decreto de reajustamento econômico, excluidas as tres especies inconstitucionais poderia restar), é imposto de que, pela lei paranaense, n. 2.666 , de 13 de abril de 1929, foi prorogada a isenção por mais dez anos, em beneficio da "Companhia Indústrias Brasileiras de Papel". 